\title{
Tumor dos Cordões Sexuais Não Classificável do Testículo
}

\author{
Unclassified Sex Cord Testis Tumor
}

\author{
Vânia GRENHA 1 , Paula SERRA ${ }^{2}$, Hugo COELHO ${ }^{1}$, Edson RETROZ1 Paulo TEMIDO $^{1}$, Alfredo MOTA ${ }^{1}$ \\ Acta Med Port 2014 Nov-Dec;27(6):787-789
}

\section{RESUMO}

O tumor dos cordões sexuais não classificável do testículo é um tumor extremamente raro, particularmente na idade adulta. Caracteriza-se histologicamente pela conjugação inespecífica de elementos estromais e epiteliais do testículo, com grau de diferenciação variável. A sua abordagem consiste na orquidectomia radical, geralmente realizada antes do diagnóstico, e posterior vigilância clínica e imagiológica. A literatura disponível sobre esta patologia baseia-se quase exclusivamente na descrição de casos clínicos. O nosso objetivo é apresentar o caso de um doente de 37 anos com um tumor dos cordões sexuais não classificável do testículo, o primeiro descrito em Portugal, e fazer uma revisão da literatura sobre o tema.

Palavras-chave: Neoplasias Testiculares; Tumores do Estroma Gonadal e dos Cordões Sexuais.

\section{ABSTRACT}

Unclassified sex cord testis tumor is an extremely rare tumor, especially in the adult. It is characterized histologically for a nonspecific combination of testis stromal and epithelial elements, with varying degree of differentiation. Treatment usually consists of radical orchiectomy followed by clinical and imaging surveillance. The available literature about this pathology relies almost exclusively on clinical cases. It's our aim to describe the case of a 37 years old man with an unclassified sex cord testis tumor, the first case described in Portugal, and to review the literature about this issue.

Keywords: Testicular Neoplasms; Sex Cord-Gonadal Stromal Tumors.

\section{INTRODUÇÃO}

Existem três grupos de tumores testiculares, de acordo com a classificação da World Health Organization, modificada em 2004: tumores de células germinativas, tumores dos cordões sexuais/estroma gonadal e tumores estromais mistos não específicos.

Os tumores dos cordões sexuais/estroma gonadal representam apenas $3-5 \%$ de todos os tumores testiculares ${ }^{1}$ e incluem os tumores de células de Leydig (cerca de $50 \%$ ), de células de Sertoli, da granulosa, os tecomas, os gonadoblastomas e os tumores não classificáveis do testículo.

Este último grupo, dos tumores dos cordões sexuais não classificáveis do testículo (TCSNCT), é extremamente raro, particularmente na idade adulta, ${ }^{2}$ e poucos casos foram descritos até hoje na literatura internacional.

Cabe-nos apresentar um caso de TCSNCT, o primeiro descrito em Portugal, ao nosso conhecimento, e fazer uma revisão da literatura sobre o tema.

\section{CASO CLÍNICO}

Apresentamos um doente do sexo masculino, de 37 anos, que foi enviado à consulta de Urologia pela presença de um nódulo duro, palpável no testículo esquerdo. $O$ restante exame físico era normal. Não apresentava antecedentes pessoais patológicos ou familiares relevantes.

$\mathrm{O}$ hemograma e marcadores tumorais ( $\beta$-HCG, $\alpha-\mathrm{FP}$ e LDH) eram normais. A ecografia escrotal revelou um nódulo sólido hipoecogénico vascularizado com 2,20 × 1,70 x 1,60 cm no testículo esquerdo (Fig. 1). A TC tóraco-abdómino-pélvica de estadiamento confirmou ausência de metastização ganglionar ou orgânica à distância (Fig. 2).

Procedeu-se de imediato a tratamento cirúrgico: o doente foi submetido a orquidectomia radical e colocação de prótese testicular à esquerda.

A anatomia patológica identificou uma lesão nodular esbranquiçada, de consistência firme e limites bem definidos com 1,70 x 1,60 cm. Microscopicamente era constituída por trabéculas e ninhos celulares sólidos, com áreas de estruturas tubulares com conteúdo eosinofilico, apresentando uma palissada periférica evidente, áreas com padrão reticulado e áreas de padrão mais difuso. Observavam-se cerca de 3 mitoses/10CGA. Relativamente aos parâmetros imunohistoquímicos, exibia positividade intensa e difusa para vimentina (Fig. 3) e inibina (Fig. 4), e focal para calretinina, AE1/AE3 e CAM 5.2, e negatividade para EMA, aFP e proteína $\mathrm{S} 100$. Em conclusão, apresentava histologia compatível com tumor dos cordões sexuais não classificável/de estroma misto do testículo, estadio pT1.

De acordo com o resultado histopatológico, foi pedido o estudo hormonal (FSH, LH e testosterona) que se revelou normal. Posteriormente, o doente foi mantido sob vigilância semestral com avaliação de sintomas, exame objetivo e TAC toraco-abdomino-pélvica. Após 2 anos de seguimento, o doente mantém-se assintomático, sem sinais clínicos ou imagiológicos de recidiva local ou à distância.

1. Serviço de Urologia e Transplantação Renal. Centro Hospitalar e Universitário de Coimbra. Coimbra. Portugal.

2. Serviço de Anatomia Patológica. Centro Hospitalar e Universitário de Coimbra. Coimbra. Portugal.

Recebido: 29 de Abril de 2014 - Aceite: 12 de Agosto de 2014 | Copyright @ Ordem dos Médicos 2014 


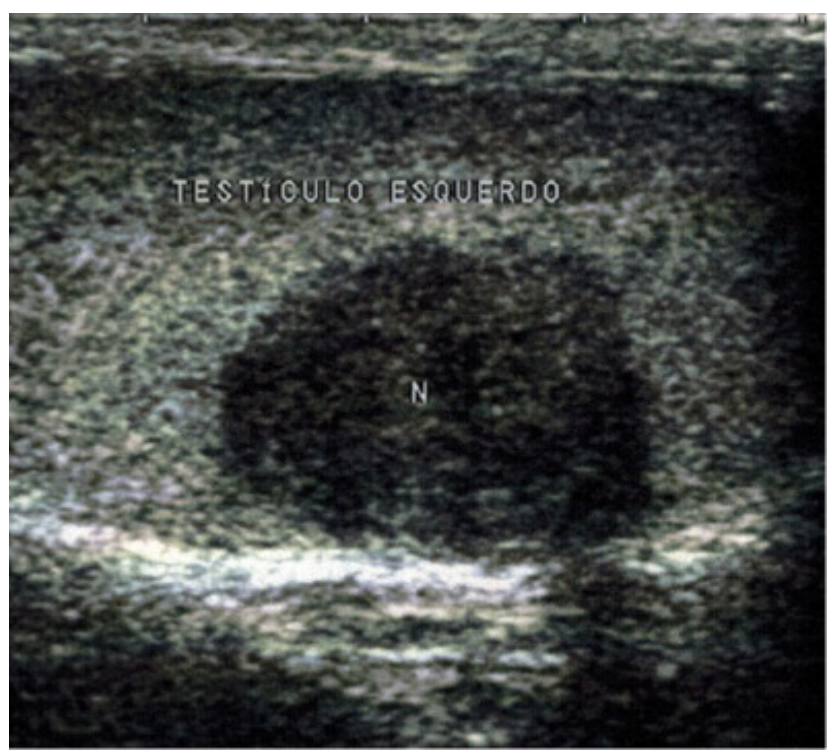

Figura 1 - Ecografia escrotal: nódulo no testículo esquerdo.

\section{DISCUSSÃO}

O TCSNCT, também designado tumor dos cordões sexuais misto ou de diferenciação incompleta do testículo (WHO classification, 2004), é um tumor extremamente raro que pode surgir em qualquer idade, embora cerca de $1 / 3$ tenham sido diagnosticados em idade pediátrica. ${ }^{3}$

Clinicamente, manifestam-se geralmente por uma massa testicular dura palpável e indolor. Ginecomastia pode estar presente em cerca de $10 \%$ dos casos. ${ }^{3}$

O diagnóstico pré-operatório é difícil pela ausência de positividade de marcadores tumorais. Componentes bem diferenciadas do tumor podem produzir hormonas sexuais como estrogénios ou testosterona, mas não permitem avaliar com segurança a extensão da doença, tanto no diagnóstico como depois, no seguimento. ${ }^{2}$

Histologicamente, os TCSNCT são constituídos por uma proporção variável de elementos epiteliais ou estromais, apresentando uma conjugação inespecífica, mais ou menos diferenciada, de tumor de células de Leydig, Sertoli ou da granulosa. ${ }^{3}$ Podem exibir uma componente de células fusiformes (spindle cells), ${ }^{4}$ padrões difusos e sarcomatóides ${ }^{3}$ ou uma completa indiferenciação celular. ${ }^{5}$

O comportamento destes tumores é incerto, embora a

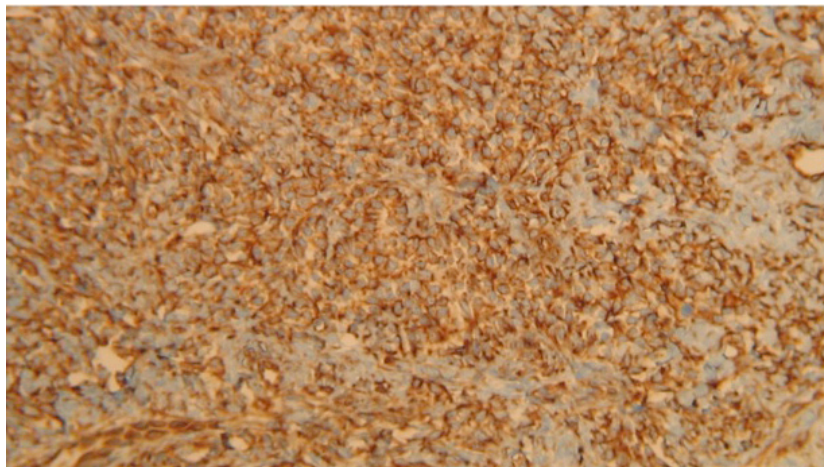

Figura 3 - Imunohistoquímica: positividade celular para vimentina.

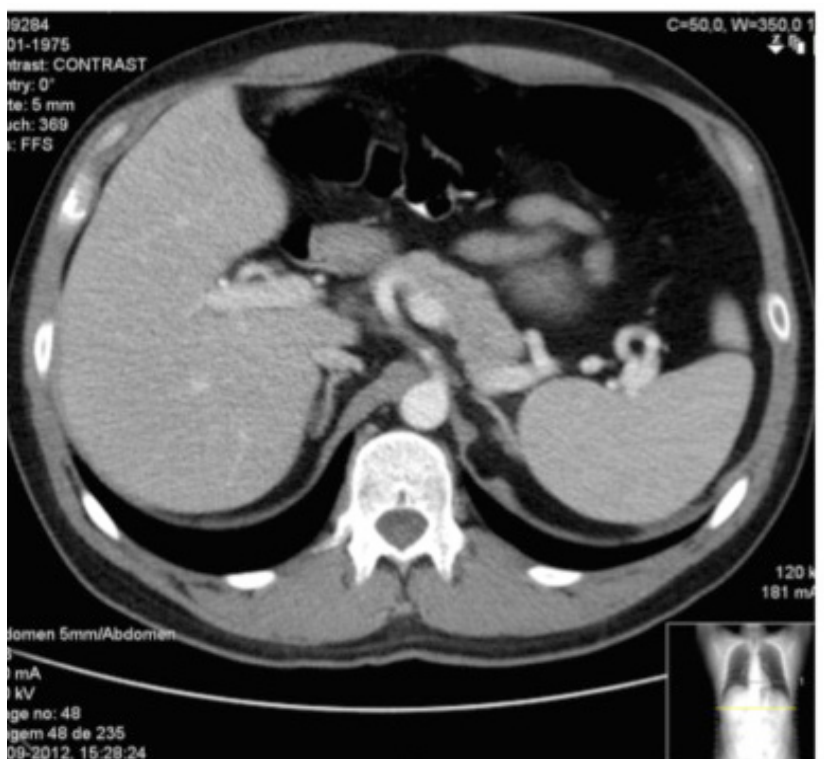

Figura 2 - TAC tóraco-abdómino-pélvica de estadiamento: sem evidência de metastização.

metastização seja rara e maioritariamente identificada no adulto. Nas crianças, os TCSNCT parecem ter um comportamento menos agressivo. ${ }^{3}$ Numa série de 43 doentes com tumor do testículo na pré-puberdade, apenas um doente com tumor dos cordões sexuais indiferenciado do testículo apresentou metastização, vindo a morrer, apesar da realização de quimioterapia. ${ }^{6}$

A determinação da história natural e de fatores de prognóstico do TCSNCT não é fácil uma vez que são muito raros e a taxa de metastização é baixa. Nos tumores dos cordões sexuais, a malignidade está associada a maior volume tumoral e idade avançada, sugerindo que a progressão para a malignidade ocorre com o tempo. ${ }^{1}$ Por paralelismo, o mesmo se pode inferir para os TCSNCT.

O diagnóstico destes tumores é geralmente histológico, dado que a abordagem de massas testiculares consiste geralmente na orquidectomia radical. Relativamente a terapêuticas complementares, a linfadenectomia retroperitoneal é uma possibilidade quando há evidência imagiológica de metastização. ${ }^{2}$ Os tumores dos cordões sexuais são na sua generalidade rádio e quimiorresistentes, pelo que habitualmente não são opções terapêuticas nos TCSNCT. ${ }^{2}$

O seguimento destes doentes deve passar por vigilância

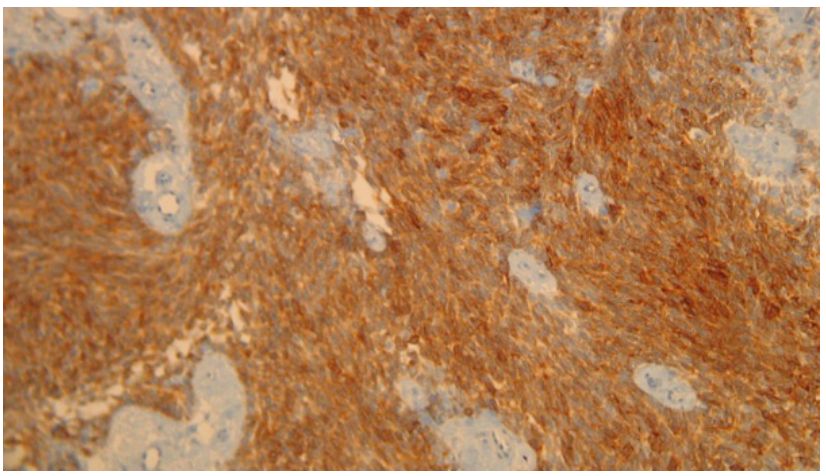

Figura 4 - Imunohistoquímica: positividade celular para inibina. 
clínica e imagiológica, com periodicidade e duração ainda por determinar. Foram já identificadas recidivas após 15 anos em tumores dos cordões sexuais/estroma gonadal. ${ }^{5}$

O doente descrito, apesar do carácter aparentemente benigno da doença (lesão pequena, localizada ao testículo, sem evidência de metastização), tem sido sujeito a uma vigilância semestral com avaliação clínica e controlo por TC tóraco-abdómino-pélvica. Trata-se de uma periodicidade baseada no paralelismo com o seguimento de outros tumores testiculares, isto se justificando contudo pelo desconhecimento atual da história natural desta doença.

\section{CONCLUSÃO}

Sendo um tumor desta raridade, seria importante dar início a estudos clínicos prospetivos, a nível nacional, de

\section{REFERÊNCIAS}

1. Featherstone J, Fernando H, Theaker J, Simmonds P, Hayes M, Mead G. Sex cord stromal testicular tumors: a clinical series - uniformly stage I disease. J Urol. 2009;181:2090-96.

2. Castelli E, Squeo MS, Faraone N, Fiori C, Burlo P, Fontana D. Undifferentiated sex cord-stromal testis tumor. J Urol. 2004;171:2375.

3. Young RH. Sex cord-stromal tumors of the ovary and testis: their similarities and differences with consideration of selected problems. Mod Pathol. 2005;18:S81-98.

4. Magro G, Gurrera A, Gangemi P, Saita A, Greco P. Incompletely forma a uniformizar dados e estratégias, para que possamos providenciar aos nossos doentes um melhor cuidado.

\section{OBSERVAÇÕES}

O caso clínico que deu origem ao artigo foi apresentado sob a forma de cartaz no Congresso da Associação Portuguesa de Urologia 2013 - Vilamoura, Algarve.

\section{CONFLITOS DE INTERESSE}

Os autores não têm qualquer conflito de interesse a declarar.

\section{FONTES DE FINANCIAMENTO}

Nenhum subsídio ou bolsa contribuiu para a elaboração deste artigo.

differentiated (unclassified) sex cord/gonadal stromal tumor of the testis with a "pure" spindle cell component: report of a case with diagnostic and histogenetic considerations. Pathol Res Pract. 2007;203:759-62.

5. Brekelbaum C, Abreo F, Fowler M, Kubricht W, Eastham J. Undifferenciated sex cord/stromal testis tumor. Urology. 2000;55:436.

6. Hofmann M, Schlegel PG, Hippert F, Schmidt P, von-Schweinitz D, Leuschner I, et al. Testicular sex cord stromal tumors: analysis of patients from the MAKEI study. Pediatr Blood Cancer. 2013;60:1651-5. 


\section{Tumor dos Cordões Sexuais não Classificável do Testículo}

Acta Med Port 2014:27:787-789

Publicado pela Acta Médica Portuguesa, a Revista Científica da Ordem dos Médicos

Av. Almirante Gago Coutinho, 151

1749-084 Lisboa, Portugal.

Tel: +351218428 215

E-mail: submissao@actamedicaportuguesa.com

www.actamedicaportuguesa.com

ISSN:0870-399X | e-ISSN: 1646-0758

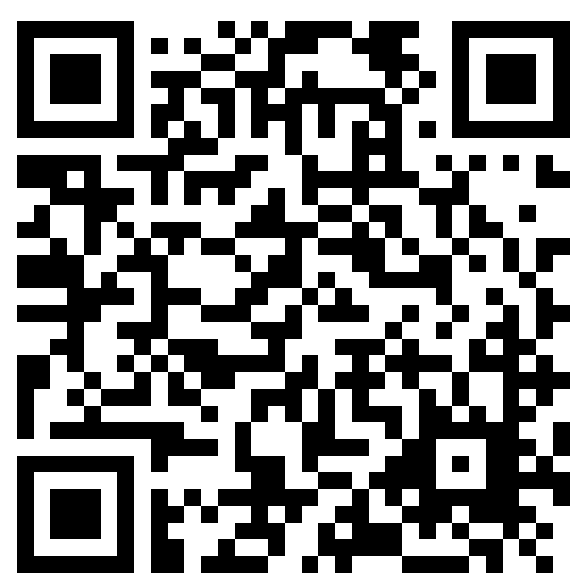

